wore estimated. The plot of surface excess of polyanion against increasing bulk concentration showed a maximum followed by a decrease to an almost constant value. A detailed model was proposed to account for this and related phenomena which was based on configurational changes of the polyanions normal and parallel to the surface. From the calculated co-ion surface excesses an estimate was made of the thicknoss of the adsorbed polyion film; this appeared, in some cases, to be greater than one monolayer.

On the following morning, under the chairmanship of Dr. J. A. Kitchener, Dr. C. H. Giles (University of Glasgow) presented a paper on "The Association of Adsorbed Organic Solutes". The adsorption of a number of organic molecules, many of them dyes, on to a variety of adsorbents was described and compared with the surface area indicated by $p$-nitrophenol adsorption. The differences relative to $p$-nitrophenol were expressed as 'coverage factors', and it was shown that these factors bore a simple relation to the molecular weight of the adsorbate. The 'coverage factors' were suggested to arise from the adsorption of the organic molecules as an aggregate or micelle. Some direct evidence for such a phenomenon was presented.

"Adsorption of Cyanine Dyes at Silver Halide Surfaces" was the title of a paper by Dr. J. F. Padday (Kodak, Ltd.). Tho surface areas of specimens of silver chloride, bromide and iodide were determined from argon and benzene vapour adsorption. It was deduced that under conditions of close packing of the cyanine dyes at the crystal surfaces the area per molecule of a given dye was different for the various halides. From this evidence and from moasurements of spectral reflectance the manner in which the substrate affected the state of the dye was discussed.

The chairman for the final session was Prof. F. C. Tompkins. In the first part Dr. I. T. Smith (Paint Research Station, Toddington) gave a paper on "An Infrared Spectroscopic Study of the Adsorption of Carboxylic Acids on Titanium Dioxide Pigments". After adsorption equilibrium had been ostablished in each case, for a variety of carboxylic acids in benzene in contact with soveral different samples of titanium dioxide, the oxide was made into disks and examined by absorption spectroscopy. The results suggested that the acids were bound to the oxides, either through a carboxylate ion, or by means of hydrogen bonds. Both types of bonding could usually be found for a given pigment. It was found that on washing the oxide with its adsorbed molecules in pure solvent the hydrogon bonded molecules, but not perceptibly tha ions, were removed. Immersion in the original acid solution restored the specimen to its original state.

The meeting ended with an extended discussion on the adsorption of polar molecules on to metal oxides. Dr. J. J. Kipling and Dr. E. H. M. Wright mentioned that stsaric acid molecules adsorbed from benzene on to silica lay flat on the surface, but on alumina and titanium dioxide were approximately vertical. They also showed that for stearic acid on titanium dioxide and alumina the adsorption was close to that expected for a localized adsorption on to lattice points. Dr. D. A. Haydon and P. T. Dawson (University of Cambridge) described the effectively irreversible adsorption at $20^{\circ} \mathrm{C}$ of formic acid from the vapour phase and stearic acid from benzene on three different dry activated rutiles. The possible reasons for a slightly lower adsorption, in all cases, of stearic acid rolative to formic were discussed. Both stearic and formic acids gave fractional covorages relative to nitrogen of approximately 0.5 . Dr. G. D. Parfitt and I. J. Wiltshire (University of Nottingham) discussed the adsorption of a homologous series of aliphatic aleohols from xylene on to a pure rutile. The amount of alcohol adsorbed showed a strong dependence on chain-length, being a minimum at octanol. Prof. Everett commented that such behaviour might be expected from his theoretical treatment of adsorption. The important part played by adsorbed water on the rutile surface in the adsorption process was also stressed.

During the meoting it was announced that it was proposed to hold a further meeting during September 17-18, 1964, in the Chemistry Department, University of Bristol, on the subject, "The Electrical Double Layer in Surface and Colloid Chemistry".

R. H. OtTewili.

\title{
METABOLISM AND PHYSIOLOGICAL SIGNIFICANCE OF LIPIDS
}

\begin{abstract}
IPID biochemistry is one of the scientific topics which Lave become prominent during the past fifteen years, due both to major technical advances easing their study and to fundamontal observations showing their importance. Thus only part of the fiold could bo surveyed at the advanced study conference on the metabolism and physiological significance of lipids, held at Cambridge during September 16-21, 1963, and supported by the Scientific Affairs Division of NATO, although about 150 participants (from institutions in sixteen countries, of which six do not belong to NATO) hoard 38 formal discourses given at nine day-time sessions, besides two informal ovening symposia, and were admirably provided by the organizers, Drs. R. M. C. Dawson and D. N. Rhodes (Great Britain), with time and electronic encouragement for free discussion.

The first major topic was lipid biosynthesis. Prof. S. J. Wakil (United States) began by describing how animals form long-chain fatty acids. First, a reductive synthesis of saturated acids from malonyl and acctyl coonzymo $A$ gives mainly palmitate; it, or longer-chain acids, can then be oxidativoly desaturated. Secondly, in the most recently examined process, acetyl coonzyme $A$ providos two carbon atoms for the reductive chain-lengthening of saturated or unsaturated acids; thus palmitoleate gives cis-vaccenate, now known to be an important component of 'oleate'.
\end{abstract}

According to Prof. K. Bloch (United States), some organisms form unsaturated acids anaerobically by the dehydration of hydroxy acids, but most do so aerobically. Only green plants can make linoleate, which is then further dehydrogenated via $\alpha$-linolenate; or, in animals, via $\gamma$-linolenate. The route used and the type of compound lipid produced by green euglenids depend on whether they are functioning as plants or animals. Photosynthetic bactoria do not produce polyunsaturated fatty acids, which may therofore be specifically concerned in plants' oxygen-yielding type of photosynthesis.

Prof. B. Shapiro (Israel) said that synthesis of triglycerides by the labile enzyme systems of liver preparations in vitro is greatly assisted by lecithin or by serum proteins, and closoly dopendent on the concentration of $\alpha$-glycerophosphate, which varies enormously under different physiological conditions in vivo and may therefore control the process.

Dr. G. Popjak (Great Britain) then showed how deutorium-labelled mevalonate and tritium-labelled pyridine nucleotides of known absolute configuration have been used to establish the precise stereochemical specificity of the reactions whereby mevalonate is converted via its pyrophosphate and isopentenyl, geranyl and farnesyl pyrophosphates into squalene, the precursor of steroids. 
Prof. G. V. Marinetti (United States) had examined glycerol metabolism in rat liver homogenates; importunt products were dihydroxyacetone, phospholipids and glycerides. Adenosine triphosphate stimulated lipid biosynthesis; with high concentrations, the only lipid formed was phosphatidic acid.

According to Dr. R. O. Brady (United States), the first specific precursor of animal glycolipids is palmitaldehyde: its acquisition from serine of one nitrogen and two carbon atoms and subsequent dehydrogenation yields sphingosine, which then reacts with uridine diphosphate galactose to form psychosine; reaction of an acyl coenzyme $A$ with the amino group to form the amide then complotes the biosynthesis of a cerebroside. Higher glycolipids probably result from the addition of furthor sugars, otc., to the cerebrosides.

Dr. J. Asselineau (France) then explained how the very large and complex molecules of the higher fatty acids of mycobacteria are formed by comparatively simple mechanisms, comprising: mothylations, such as that of oloato to give tuberculostearate; the condensation of propionate residues with each other and with higher acids yielding the phthienoic and mycocerosic acids; and finally, the condensation of long-chain $\alpha$-hydroxy acids to give the branched-chain hydroxylated mycolic acids of nearly 90 carbon atoms.

Two plant fatty-acid-forming systems described by Prof. P. K. Stumpf (United States) resembled animal mechanisms examinod by Prof. Wakil; one synthesized saturated acids from malonyl coenzyme $A$, while the other lengthened the carbon chain of assorted acids, ricinoleato boing ono product. Thirdly, the safflower soed made linoleate from acetyl rather than malonyl coenzyme $A$; a single gene controlled the synthesis of linoleate instead of oleate.

Discussion of the further metabolism of lipids began with an examination of the enzymatic hydrolysis of fats. Dr. P. Desnuelle (France) has developed a simple and efficient means of purifying pancreatic lipase; it requires finoly emulsified water-insoluble $\alpha$-glycorides as substrates, and the liberated fatty acids prevent long-chain $\beta$-monoglycerides also produced from isomerizing to $\alpha$-monoglycoridos, which would be poor substrates for mucosal fat re-synthesis. Any short-chain $\beta$-monoglycerides, however, isomerize and are destroyed.

Prof. L. L. M. van Deenen (Holland) went on to describe how the unambiguous synthetic work of his laboratory has firmly established the spocificitios of the phospholipases, which can now safely be used to elucidate the structures of natural lipids. Thus it has been shown unequivocally that the plasmalogens and the batyl or chimyl phosphatides are $\alpha^{\prime}$-glyceryl ethers, not $\beta$-glyceryl compounds as first thought; again, all phospholipases attack phosphatidylglycerol C, yielding a diglyceride and $D$ - $\alpha$-glycerophosphate.

Tho substrate specificitios of several phospholipasos have been shown by Dr. R. M. C. Dawson (Groat Britain) and his colleagues to be matters not only of chemical structures but also of micollar surface charges, which ean be measured as electrophoretic mobilitios and regulated with suitable counter-ions. This can even be demonstrated with the specific phosphatases attacking the polyphosphoinositides, which are virtually water-soluble.

The unusual metabolism of these very polar compounds in animal tissues was then discussed by Dr. . N. Hawthorne (Great Britain). They probably arise from the phosphorylation of monophosphoinositide, which is in turn formed by a unique reaction botwoen cytidine diphosphate diglyceride and free inositol. A possible function of the inositol phosphatides may be the transport of divalent cations across mitochondrial membranes.

The gaps in our knowledge of the metabolism of plasmalogens wore thon exposed by Dr. E. F. Hartree (Great Britain); the fatty acid of choline plasmalogen is a major source of energy for mammalian spermatozoa, but little is known about the enzymatic rupture and synthesis of the $\alpha^{\prime}-1$-alkenyl ether bond. It seems to be formed from a long-chain acyl-coenzyme $A$, yet such compounds can be reduced enzymatically giving free aldehydes which are not incorporated into plasmalogens.

At an informal and lively symposium that ovening, many examples were given of the great but mysterious physiological importance of the structures of certain fatty acids, which is only partly explicable by their physical properties but also depends on the particular lipids in which they occur.

The conference next examined the digestion and absorption of fat. Prof. B. Borgström (Sweden) explained how triglycerides are emulsified by bile salts and digested by pancreatic lipase to give free fatty acids and $\beta$-monoglycerides; this mixture is readily absorbed, helped by the re-synthesis of fat in the mucosa. In the absence of bile salts, lipase itself catalyses triglyceride synthesis.

Dr. G. H. Hübscher (Great Britain) then outlined two other and probably more important processes of mucosal fat re-synthesis, both requiring coenzyme $A$ for the acylation of $\alpha, \beta$-diglycerides, which arise either directly from $\beta$-monoglycerides or by enzymatic dephosphorylation of phosphatidic acids produced by acylation of L- $\alpha$-glycerophosphate. The phosphatic synthesis needs two new co-factors, ono thermolabile, the other probably related to carnitine.

Quantitative ideas of fat absorption and transport in vivo have, according to Dr. A. M. Dawson (Great Britain), been seriously distorted by technical difficulties of measurement. It now appears both that free glycerol can be an important source of glycerophosphate for mucosal triglyceride re-synthesis, and that up to a third of the long-chain acids of ingested fat pass into tho portal vein in the free stato.

Drs. W. M. F. Leat and T. Gillmon (Great Britain) then dealt with the absorption, transport and cloarance of fat by ruminants; they absorb neutral fat poorly and cannot tolerate it as an intravenous emulsion, but readily absorb free fatty acids which are then kept at a steady level in the plasma by hormonal regulation.

'The conference then turned to its second major theme, the physiological significance of lipids in the general economy of animals and bacteria, beginning with a session devoted to large-scale evonts in living animals.

Dr. D. S. Robinson (Great Britain) began by suggesting that only a small amount of fat is supplied to tissues by mammalian blood as free fatty acids, since a large proportion of any available are rapidly converted by the liver into plasma lipoprotein triglycerides; the latter are readily used by the tissues after hydrolysis by lipoprotein lipase, which is probably in the capillary endothelium and is controlled both by the tissues' needs and by the supply of fat.

Even in ruminants, said Dr. E. F. Annison (Great Britain), isotope dilution experiments have shown that glucose is the main substrate for respiration in vivo; longchain fatty acids are used anabolically, as in other animals, although acetate is oxidized to some extent.

Dr. R. G. Macfarlane (Great Britain) summarized the confused history of theories connecting lipids with blood clotting. Two stages in this very complex procoss still appear to require lipids, oven after the elimination of misleading phenomena such as non-specific 'contact activation' and the massive thromboses produced by free fatty acids. The lipids' micellar surface charges seem to be more important than their chemical structures.

Ruminants have poculiar depot fats because, said Dr. A. G. Garton (Great Britain), all the fatty acids which they absorb arise either by microbial alteration of the diotary lipids or by digestion of the rumen micro-organisms themselves. The former process yields short-chain acids from glycerol and galactose, and partially hydrogenated and isomerized long-chain acids; branched-chain acids are derived from bacterial protoplast membranes. 
The ruminant's milk fatty acids, on the other hand, have, according to Prof. G. Peeters (Belgium), been shown by recent experiments in vivo, and with perfused isolated udders, to be mostly synthesized from blood acetate, with a small contribution from propionate; long-chain acids, however, can be obtained from the plasma's scarce triglycerides, but will only exchange with its free fatty acids, without net uptake.

The next session was concerned with the locations and properties of lipids in the surfaces and internal parts of cells. Prof. W. Bartley (Great Britain) described the lipid compositions of the intracellular organelles of rat liver and brain. The fatty acids are characteristic of the lipids rather than of the organelles, except that 'essential' fatty acids are unusually abundant in mitochondrial cardiolipids, which may be functionally important, being the only mitochondrial lipids remaining in oxidatively phosphorylating 'digitonin particles'.

Possible structures of animal cell membranes were then discussed; Drs. J. A. Lucy and J. T. Dingle (Great Britain) demonstrated that certain lipid mixtures could give electron micrographs showing hexagonal arrays of uniform spherical micelles; on the other hand, Drs. A. D. Bangham and R. Horne (Great Britain) had obtained pictures confirming the more usual idea of a lamellar structure.

Dr. M. G. Macfarlane (Great Britain) then surveyed the lipids of bacterial protoplast membranes, which contain somo unique compounds such as the phosphatidyl glyceryl amino-acids and diacyl glyceryl mannose, besides resembling mitochondria both functionally and in being rich in acidic phosphatides. Their fatty acids are mostly saturated, but a large proportion have highly branched chains, and hence show physical resemblances to the polyunsaturated acids essential for higher animals.

Drs. L. E. and M. R. Hokin (United States) then described how secretory activity and the turnover of phosphatidic acid labelled with phosphorus-32 in avian pancreas or salt gland are reversibly stimulated by pancreozymin or acetylcholine in vitro; when the hormone is removed, the label goes to phosphatidylinositol. This may represent the activation and inactivation of a sodium carrier by the conversion of phosphatidylinositol to phosphatidic acid and vice versa.

The second evening symposium was devoted to a popular and stimulating discussion of recent progress in the separation and analysis of lipids by chromatographic methods, with perhaps the greatest interest being shown in thin-layer chromatography.

Some pathological and endocrinological aspects of lipid metabolism were then examined. Dr. C. R. C. Heard and Prof. B. S. Platt (Great Britain) reported some deleterious effects of low-protein diets on young animals. With the worst diets, even a trace of casein was very beneficial, whereas extra carbohydrato led to obesity, cdema, fatty livers and low glucose tolerance, besides severe regression of the thyroid and, suggestively, of the $\beta$-cells of the islets of Langerhans.

Dr. K. R. Rees (Great Britain) then showed how another defect in protein metabolism may be the direct cause of the fatty livers induced by, for example, poisoning with carbon tetrachloride; the poisoned liver converts plasma free fatty acids into triglycerides as usual, but can no longer return them to the plasma in low-density lipoproteins. Certain detergents, however, will move this fat into the bloodstream, thus preventing fatty livers.

Prof. W. Freinkel (United States) had found that, in vitro, adipose tissue's utilization of glucose for respiration and fat synthesis was greatly and immediately stimulated by insulin, the offect persisting somewhat after the hormone's destruction, while thyroid slices treated with thyroid stimulating hormone oxidized more, not less, glucose when fatty acids were added, and incorporated them into kephalins rather than triglycerides: these effects resembled events in vivo.
Dr. G. B. Ansell (Great Britain) reviewed present knowledge of the effects of electricity and drugs on lipid metabolism in the nervous system, and described some experiments with chlorpromazine. It was known to increase the turnover of phosphatidic acid and phosphatidylinositol in brain slices, but decreased that of lecithin, probably by inhibiting the formation of cytidine diphosphate choline.

Leucocytes will ingest starch particles by phagocytosis, or, when stimulated by deoxycholate, inulin solutions by pinocytosis. Prof. M. L. Karnovsky (United States) reported experiments in which these phenomena, presumably requiring the formation of much new cell mem. brane and hence expected to stimulate phospholipid metabolism, were indeed accompanied by six-fold increases in the turnover of phosphatidic acid, with smaller increases for other acidic phospholipids.

The last afternoon session was dovoted to the nervous system. Prof. R. Rossiter (Canada) gave an account of the ability of brain to synthesize phospholipids in vitro. Preparations from young animals show the usual 'Kennedy pathway', as well as a base-exchange reaction interconverting phosphatidylethanolamine and phosphatidylserine, a decarboxylation of the latter, and an especially rapid synthesis of plasmalogens. Phosphatidylinositol is rapidly formed from cytidine diphosphate diglyceride; di- and tri-phosphoinositide aro even more actively metabolized.

On the other hand, Dr. A. N. Davison (Great Britain) and his colleagues have confirmed that the myelin sheath. ing the larger nerve fibres of the central nervous system does not metabolize in adults; it has a negligible enzyme content, and isotopically labelled cholesterol, cerebrosides, sulphatides, sphingomyelin, ethanolamine plasmalogen, phosphatidyl serine and proteolipid proteins, once laid down in young animals, persist throughout life.

Prof. R. H. S. Thompson (Great Britain) went on to outline the evidence for a possible explanation of the disappearance of myelin, normally so stable, from the lesions of disseminated sclerosis. An observed deficiency of essential fatty acids could cause mitochondrial failure in the metabolically active oligodendroglia, and hence cell lysis with the release of phospholipases, known to occur in brain and to form the myelinolytic lysolecithin, which also lyses cells to release more phospholipase; this autocatalytic process will stop only when the systems removing lysolecithin regain control.

Prof. L. Svennerholm (Sweden) then outlined the complex interrelations between the gangliosides of brain neurones, in connexion with Tay-Sachs disease. The infant victims' brains accumulate excessive quantities of an unusually simple ganglioside, due to a deficiency either of the enzymes normally destroying it or of those which would normally use it for the synthesis of higher gangliosides by attaching further galactose, $N$-acetylgalactosamine and $N$-acetyl-neuraminic acid residues to it.

Prof. F. R. N. Gurd (United States) opened the final meeting by demonstrating, from the structure of myoglobin, tho specific bonding of 'lipids', such as the nonpolar groups of hæm, with the globin's non-polar aminoacid residues, which are collected together away from the protein's polar regions.

Dr. D. E. Groen (United States) went on to describe analogous properties of mitochondria; careful extraction with aqueous acetone leaves their protoin skeletons intact but abolishes their enzymatic activities, which can then be restored by treatment with aqueous emulsions of the extracted lipids. Lecithin will reactivate the dehydrogenases, but both coenzyme $Q$ and acidic phosphatides-
preferably cardiolipins-are needed for oxidative phosphorylation, which seems to involve stoichiometric reactions between the cytochromes and groups of the lipids' polar 'heads', the hydrophobic 'tails' being attached to the non-polar regions of the protein skeleton. 
Taken together with observations by other speakers, including Prof. K. Bloch, Prof. W. Bartley and Dr. M. G. Macfarlane, Prof. Gurd's and Dr. Green's findings suggest one possible aspect of the 'essential' nature of particular fatty acids. Thoso acids are prominent in the lipids of the main energy-yielding apparatus of the bacterial, plant or animal cell; perhaps the non-polar regions of certain vital sections of the protein skeleton of this apparatus require specific structures in the hydrophobic 'tails' of the lipids which must be present for full enzymatic activity to be displayed.

\section{F. H. Sloane-Stanley}

\section{CHARACTERIZATION AND USES OF HUMAN DIPLOID CELL STRAINS}

\begin{abstract}
A SYMPOSIUM on "The Characterization and Uses of Human Diploid Cell Strains (HDCS)", sponsored by the Permanent Section on Microbjological Standardization of the International Association of Microbiological Societies, was held in Opatija, Yugoslavia, during Septembor 24-26. Ninety-six delegates from 18 countries attended. The sessions covered the following topics: (1) The management of human diploid cell strains. (2) Biochemical, cytogenetic and immunological studies on human diploid cells. (3) Virus spectrum of human diploid cells. (4) Production of human virus vaccines in human diploid cell strains. (5) Results of clinical trials on the use of vaccines prepared in human diploid cell strains.

Many laboratories receiving the human diploid cell strains reported their success in propagating the cells and attributed most of their early failures in handling these strains to variations in media constituents. The cells showed the classic normal human diploid karyotype until approximately tho 40 th cell generation.

It was reported that, at least for some loci, cultured diploid cells carry and express the genes of their donor. The human diploid cell strains retain the donor's chromosomal complement; they also maintain biochemical and immunological properties of the donor cells. In a sense these observations are complementary, for they indicate at two structural levels an apparont genetic resemblance between the cultured cells and the somatic tissues of the host.
\end{abstract}

The numerous attempts to isolate latent viruses from these cells have been unsuccessful. Dangers from extraneous oncogenic viruses, inherent in the use of primary explants of animal tissue, are largely circumvented in the opinion of many workers when human diploid cell strains are used for vaccine production.

Investigations on the virus spectrum of human diploid cell strains indicated their susceptibility to many viruses. These strains were thought to be particularly valuable in work with the rhinoviruses which cannot generally be devected in other cell substrates. Since different human diploid cell strains vary in their sensitivity to rhinoviruses, it was felt important to use the most sensitive strains.

Both live attenuated and killed vaceines for parenteral inoculation or oral administration have been made in human diploid cell strains from poliovirus, rhinovirus, adenovirus, varicella, measles, vaccinia and rabies. Following adaptation to human diploid cell strains, all viruses investigated were said to give yields equal to those in other cell systems. Investigations with poliovirus showed that they retained their genetic markers when propagated in human diploid cell strains.

It was urged that all laboratories using human diploid cell strains for vaccine production limit themselves to a fow standardized cell strains, since the use of a wellcharacterized tissue culture system is as logical and necessary as the use of a well-charactorized virus to be propagated in this system.

Clinical investigations on a number of virus vaccines are in progress. It was reported that an oral poliomyelitis vaccine produced in human diploid cell strains has already been successfully tested in a large-scale fiold trial and that no untoward reactions have been noted in 7,000 subjects who have received vaccine during the past two years. It was also reported that such vaccines proliferated in the gastro-intestinal tract and elicited an antibody response.

On the basis of the investigations suggesting the feasibility of large-scale production of virus vaccines in human diploid cells strains, a sub-committee of the conference drafted "Minimum Requirements for Human Diploid Cell Strains to be Used in Vaccine Preparation". These requirements were presented to the symposium participants and adopted at a plenary session.

LigONARD HAYFLICK

Frank T. Perkins

Robert E. STEVENSON

\section{SCIENTIFIC RESEARCH IN NEW ZEALAND}

$\mathrm{T}$ HE report of the Department of Scientific and Industrial Research, Now Zealand, for the year ended March 31, 1963*, includes the Minister's statement, the report of the Council, the longer report of the Secretary, to which are attached brief reports from tho various Divisions, the Incorporated Research Associations, and on granted-aid research in the Cawthron Institute, Lincoln College, Massey University College of Manawatu, and the Industrial Development Department, University of Canterbury. The fifth annual report of the Ross Dependency Research Committee is appended, to which, as to the Divisional reports, a list of publications is attached. The Council in its report reiterates the view that a much more comprehensive review of research is needed than was

* New Zealand. Report of the Department of Scientific and Industrial Research for the year ended 31 March, 1963. Pp. 87. (H. 34.) (Wellington: Government Printer, 1963.) $3 s$. given by the Royal Commission on State Services, but supports the proposal to replace the present Council, which is advisory only to the Department of Scientific and Industrial Research, with a National Research Council responsible for advising the Government on all aspects of research in Government Departments. The new Council should be advised by a number of export committees, but the Department of Scientific and Industrial Research must retain many of the existing expert committees. Research and development expenditure in New Zea. land in 1961-62 was still only 0.3 per cent of the gross national product or $£ 1.9$ per head of the population, the Department's gross expenditure of $£ 2 \cdot 19$ million being 0.163 per cent of the gross national product. Staff at March 31, 1963, numbered 1,229, including 455 scientific officers, compared with 1,170 and 442 , respectively, the previous year. An increase of 60 in the staff has been 